\title{
The Democratic way of Coaching and Motivation for Student-Players'
}

\author{
* Mr. Nisar Ahmed Khaskheli (Corresponding Author) \\ ** Dr. Hakim Ali Sahito \\ *** Dr. Javed Ali Soomro
}

\begin{abstract}
This research was carried out to know the central subject of the assessment with the relationship of a democratic coaching style on the student-players of motivation. Therefore; the survey study was conducted on understudy players of Badminton at Sukkur-area, Sindh. The players of twenty Colleges and twenty departments of Shah Abdul Latif University, Khairpur as 100 from each $(N=200)$ participated. A questionnaire was utilized as a data collection instrument. The disclosures imply that a tremendous piece of players was experienced for the closest and helpful results of a democratic coaching style on the players' motivation. The frequencies and percentages were differently computed with the overall methods as; 2.36, 2.39, 2.38, 2.31, 2.38, 2.45, and 2.49 which were different from each other fundamentally. The after effects of examination proposed that the training and coaching programs produce and build up the thought of specific training style to motivate the player to compete effectively, may be arranged and the competitions like between clubs, Inter-department, Inter-school, Inter-collegiate, Inter-region, and inter-varsity, be organized whereby the players may profit open entryways for participation and may show their level of skill capacity, performance, and motivation.
\end{abstract}

Keywords: Democratic Coaching, Effect Assessment, Players' Motivation Introduction

The performance progress of players towards a condition of aptitude is generally encouraged through tedious practice or "penetrating" by coaches, a methodology grounded in the standards of conscious practice (Ericsson et al., 1993). Drill based practice sets out a critical persuasive issue for players and trainers the same in that it includes a lot of redundancy which can be both repetitive and drilling (Mitchell, 2006). Coaching is a mind-boggling task and required the utilization of various methodologies and practices to satisfy numerous desires. So sports coaches must have great information, need to create capabilities or abilities, and high motivation in completing duties to deliver quality competitors (Fouss \& Troppmann, 1981). The coach-competitor relationship isn't any extra to, or results of, the training procedure, nor is it dependent on the players' exhibition, age, or sex rather it is the establishment of instructing. The mentor and the competitor deliberately build up a relationship, which is portrayed by developing gratefulness and regard for one another as people. By and large, the relationship of coach and player is implanted in the dynamic and complex training process and gives the methods by which mentors' and competitors' needs are communicated and satisfied (Jowett \& Cockerill, 2002). Explicit instructing practices are identified with increments in execution, particularly when genuine and favored training practices are consistent (Weinberg \& Gould, 2003). It has been demonstrated that the conduct of a mentor may decide his competency in structuring compelling preparing henceforth impact astounding accomplishment among his competitors (Myers et al., 2006). Motivation is a regularly contemplated point in different regions of sports logical exploration studies, for example, instruction, business, practice, etc. In particular, motivation is a gadget that portrays why a few people decide to take an interest in different exercises, invest more energy, and persevere longer than others. Motivation is a significant mental variable in sports and its need to accomplish an elevated level of rivalry (Khan et al., 2011). An equipped coach that gives high fulfillment to his players may inspire them to perform certainly in their games. In this way, an equipped coach ought to have a few abilities in picking the correct methodology, procedure, and tune of language when moving toward their competitors (Chiu et al., 2014). Ultimately, attention on what one individual does to another may not precisely think about what goes among mentors and

\footnotetext{
* Department of Physical Education and Sports Sciences, Sukkur IBA University, Sindh-Pakistan

** Department of Zoology working at DPRI, Faculty of Natural Sciences, SALU- Khairpur, Sindh-Pakistan

*** Centre for Physical Education, Health \& Sport Sciences, University of Sindh, Jamshoro, Sindh-Pakistan
} 
their competitors. It is commonly acknowledged that the impacts of a coach on a competitor's presentation are significant. Since the coaches are the pioneers for ability and self-awareness of players and the pioneers for seeking after athletic targets, training got and its styles expanding consideration during the previous twenty years. The autocratic style is considered by numerous Coaches to be a significant factor in a competitor's prosperity. Most Coaches utilize diverse authority styles one after another or another to various circumstances. A few styles are more appropriate in specific circumstances than others.

\section{Badminton}

Badminton is a game that is strikingly played out everywhere throughout the world. This amusement is performed at all levels by methods for the individuals having a spot with indisputable age social affairs (Shariff et al., 2009). Badminton is an indoor game that is played with a lightweight racket and a shuttlecock. Truly, the shuttlecock was a little plug with a side of the equator with 16 geese that were appended and weighing around 5 grams. Thus, these sorts of shuttles may in any case be valuable these days. However, the vans by and large utilized are produced using engineered materials are additionally permitted by BWF which is a short name for a badminton world organization. In this way, the exposition on my preferred game badminton is knowledge into my preferred game and the standards and guidelines chased after the world. The name badminton depends on the nation domain for the dukes of Beaufort in England. Likewise, the game was the first run through playing there in 1873. Furthermore, the underlying foundations of the game are additionally followed to old China, Greece, and India. Additionally, this game is supposed to be firmly identified with kids' down shuttlecock and battledore. The badminton world league broadly known as BWF is the overseeing body for the game around the world. Likewise, this overseeing body was shaped in the year 1934 . Moreover, badminton is popular in Indonesia, Japan, Denmark, and Malaysia. The principal title under BWF was held in the year 1977. Additionally, there are various national, territorial, and zonal competitions which are held in numerous nations. One of the well-known competitions in badminton is the All-England titles. Moreover, the universal and notable competitions incorporate the Uber cup and Thomas cup. Badminton was presented in the Olympics without precedent for 1972 as an exhibition sport. While; during, 1992 Olympics, this game was under the full decoration class. Likewise, the opposition incorporated men's just as ladies copies and blended pairs were presented in the 1996 Olympics (https://www.toppr.com). According to the estimation of BWF, this redirection is before long playing with the guide of more than, 200 million individuals on the earth and over a thousand took territory in an arrangement of disputes and contentions around the globe (Alam et al., 2009).

\section{Coaching}

A coach assumes a significant job in the "prosperity" and execution of players in competitive Sports. Predominant and imperious training styles could be a wellspring of worry among competitors, influencing temperament states, and glucocorticoid reaction (Oberle \& Schonert-Reichl, 2016). The word coaching was first used in mid of the fifteenth century in the Hungarian town of Kocs (explained "tutor"), from that point this word mentor spread wherever all through Europe. By mid of nineteenthcentury word mentor was used by Oxford University slang for a guide; one who brings or asks his understudies through a test. The word moreover appears in the advancement of George Eliot, an English essayist, who was woman, the certifiable name was Marry Anne, as the Sports Coach, the oxford mentor looked somewhat like the propelled version, simply preparing and presenting data as would any dexterous instructor on conventional lines. A coaching and learning process wherein two people may contact with each other, one individual has information and various needs course and bearing (Jane, 2009). The training is a specialist attempt that allows the players to participate in sports contentions with feasible practices (McDonell, 2016). Several authors have proposed that positive discourse, reflection, and great friend full of feeling social connection advance better learning, a reality that could be magnificent methods by which to arrive at better-specialized aptitudes and execution. Previously studies additionally noticed how coaches with various initiative styles could get engaged with the preparation of youthful competitors, i.e., by halting preparation when players were confronting medical issues, tweaking hormonal action, or indicating a negative full of feeling valence to the preparation load (Nazarudin et al., 2009). However, some beneficial outcomes in the common habitat were likewise watched, for example, vulnerability decrease or intragroup consistency improvement in regards to social collaborations, particularly when the social chain of importance was 
acknowledged by these types of researchers accordingly (Magee and Galinsky, 2008), respectively. All things considered, equitable instructing could improve and build players' fearlessness, strength, and execution. Coaches ought to have the option to set up possibilities, keep up the force of the preparation procedure, give the motivation to learn, and over satisfactory criticism to accomplish better execution (Olusoga et al., 2009; Van Duijvenvoorde et al., 2016). A few Coaches like to animate vote based and dynamic investment in the preparation procedure (e.g., empowering the collaboration and full of feeling articulation inside the gathering to accomplish their serious targets) (Light \& Harvey, 2017). Delayed presentation to aversive upgrades may restrain the foundation of an equalization (e.g., inspiring feelings of disappointment, worry, and outrage), influencing competitors' adjustment procedure to rivalry (Keatlholetswe \& Malete, 2019).

\section{Motivation}

Motivation has been a focal point when all is said in done brain science for a very long while, just as, more as of late, in-game, and exercise brain research (Roberts, 2001). Similarly, incredible intrigue has been appeared in the physical movement of youth, either from the perspective of game inclusion and execution or action for wellbeing (Sallis et al., 2000). The Coaches regularly resort to a scope of behaviorist-type procedures including verbal admonishment, discipline, pay off (camouflaged as 'prizes'), or dangers to advance elevated levels of inspiration in competitors (Deci \& Ryan, 2000). Hypothetical points of view on game and exercise inspiration are various. In any case, when examining youth in physical settings, a social-intellectual perspective has gotten predominant in the previous two decades. Specifically, sports analysts have energetically grasped the fundamentals of the accomplishment objective hypothesis (Duda, 2001). In sports; coaching, motivation is significant because numerous researchers and educators are keen on comprehension and clarifying enthusiasm as an impetus for proficient development and the arrangement of an uplifting disposition of understudies to physical movement through dynamic cooperation and a sound way of life, the progress of outer inspiration to inside and outside direction and accomplishment objectives. It is intriguing that is a guide for our feelings, activities planned for accomplishing better and the sky is the limit from there. All experts, imperative self-restraint, dynamism can be clarified based on motivation, scheming (Ivanovo et al., 2019). Accomplishment motivation can be characterized as the competitor's inclination to approach or maintain a strategic distance from a serious circumstance. From a more extensive perspective, it incorporates the idea of achievement, or desire to exceed expectations. The craving to make progress in sport isn't an intrinsic drive, for example, yearning or thirst, yet is likely one that is created or learned in the donning condition (Khan et al., 2011). The motivation might be characteristic, outward, or non-motivated, intrinsic motivation alludes to taking part in a movement for the joy and fulfillment one gets from direct investment (for example pleasure). Conversely, extraneous motivation is instrumental and is experienced when somebody takes part in a movement for motivating forces that reach out past those characteristics in the action (for example to acquire a prize). At long last, non-motivation speaks to an absence of possibility between one's activities and their results. For instance, competitors who state that they truly don't have an unclear idea of why they play badminton any more are showing non-motivation toward their game. The past examination has uncovered that self-decided types of motivation (natural motivation and recognized regulation) are emphatically connected with positive results (e.g., better learning, improved execution) while least self-deflect mined types of motivation (outside guideline or non-motivation) are related with negative results (e.g., less perseverance, less fortunate athletic execution (Ramirez et al., 2010). Various investigations have demonstrated the effect of mental variables on sports execution (Crespo, 2002). In this way, there is a need to give positive reasoning and better mental aptitudes to tackle the issues that may emerge on account of nervousness. If it isn't dealt with well or confused, the player will lose control and their exhibition will diminish (Gualberto \& Wiggins, 2008).

\section{Research Gap}

The development of motivation, enthusiasm for accomplishment in sports stays a significant undertaking in sports instruction, as Sports Coaches researchers, and instructors study the ideas and definitions related to the advancement of physical movement. The discoveries of different explore exhibit a specific impact of coaches on the players. The ability of Coaches to force the players assumes a key job to have productive and successful outcomes in any game. While discussing Pakistan, particularly the Sukkur locale where the investigation led, and a colossal number of players having a place with different games are the individuals who don't have a proper and normal 
instructing condition. Countless schools and colleges don't have their own designated Coaches. In the College instruction framework, the Director of Physical Education (DPE) works additionally as a Coach of different games including Badminton. It was accounted for before this examination, that DPEs of different Colleges apply democratic coaching style to prepare the players through the preparation and training meetings. A decent number of understudy players of Badminton concentrating in universities, having a place with Sukkur, area Sindh have been believed to take an interest at top-notch positions Badminton competitions and to contend unhesitatingly in occasions with triumphant outcomes, for example, between locale, Sindh Games and national games. Thusly an inquiry emerged to discover the reality of the impact of democratic coaching style on the motivation of understudy players of Badminton.

\section{Hypothesis:}

$\mathbf{H}_{\mathbf{0}}$ Democratic coaching style affects negatively on the motivation of student-players of Badminton.

$\mathbf{H}_{\mathbf{1}}$ Democratic Coaching Style effects positively on the motivation of Badminton players.

\section{Research Methodology}

The assessment was conducted to find the impact of democratic coaching style on the players of Badminton who are concentrating on different controls to compete in the matches. Understudy players of Badminton learning at Shah Abdul Latif University Khairpur (SALU) and its Colleges of the Sukkur locale were picked as the population of the study. The Colleges of SALU, Khairpur located in Sukkur, was visited by the cooperation of Directors of Physical Education (DPEs) before the start of examination to get to the understudy players of Badminton. Using comfort testing procedure, 20 Colleges were picked as an examination test, as suggested by the respective DPEs, whose understudy should, in any event, have played at least inter-class, Inter-department, Inter-collegiate or inter-varsity Badminton tournaments, while discussing University, Sports office of SALU Sports-festival was arranged in which inter-department Badminton tournament was also the part of the eve. List alongside names of players was present in the Sports Section of University which was used to contact the players to conduct a survey. The sample size of the examination was forty groups as $(\mathrm{N}=200)$ players of Badminton, as one hundred from the Colleges and one hundred from the various teaching departments of the University. The assessment was limited to the understudy players (youngsters) of B. A part-I and II, BSC part-I and II, B. Com part-I and II of degree (young men) Colleges of locale Sukkur and Badminton (youngsters) contenders of different departments of SALU, Khairpur, registered in various degree programs.

\section{Statistical Analysis}

An organized overview survey as, Coaching Efficacy Scale (CES, Feltz et al., 1999) which involves 5 areas of coaching, was utilized as a data collection scale. The frequency, percentage, and mean were computed by the usage of the Statistical Package of Social Sciences (SPSS) variant 22.

\section{Results}

Cronbach's Alpha test was driven, to ensure the consistency of information. The result of Cronbach's Alpha test was found as 0.92 which is strong. The data arrangement instrument that similarly fuses decrees for the examination of impacts of just coaching style on the motivation of Badminton players, as referenced in table-1. The examination shows that larger piece of responses is for useful results of democratic coaching style on the motivation of Badminton-players with a most extraordinary frequency starting from the outset articulation, $13,6.5 \%, 63,31.5 \%, 124,62.0 \%$ with a mean 2.36 , second explanation, $16,8.0 \%, 72,36.0 \%, 112,56.0 \%$ with a mean 2.39 , third item, $7,3.5 \%, 105$, $52.5 \%, 88,44.0 \%$ with a mean 2.38 , fourth statement $14,0.7 \%, 97,48.5 \%, 89,44.5 \%$ with a mean 2.31 , fifth item $6,3.0 \%, 108,54.0 \%, 86,43.0 \%$ with a mean 2.38 , sixth item $5,2.0 \%, 105,52.5 \%, 90$, $45.0 \%$ with a mean 2.4 and seventh as last thing $90,45 \%, 8,4 \%, 114,57 \%$ with a mean 2.49 this appraisal implies that there are close productive results of democratic coaching style on the motivation of Badminton-players, concentrating on respective Colleges and University. 
Table. 1 statistical analysis

\begin{tabular}{|c|c|c|c|c|}
\hline Statement & Option & Frequency & Percentage & Mean \\
\hline $\begin{array}{lll}\text { Helps } & \text { player } & \text { to }\end{array}$ & Not at all & 13 & 6.5 & 2.3600 \\
\hline \multirow[t]{2}{*}{ maintain confidence } & Moderately & 63 & 31.5 & \\
\hline & Extremely & 124 & 62.0 & \\
\hline \multirow{3}{*}{$\begin{array}{l}\text { Psychologically } \\
\text { prepares the player }\end{array}$} & Not at all & 16 & 8.0 & 2.3900 \\
\hline & Moderately & 72 & 36.0 & \\
\hline & Extremely & 112 & 56.0 & \\
\hline \multirow{3}{*}{$\begin{array}{l}\text { builds the Self-Respect } \\
\text { of player }\end{array}$} & Not at all & 7 & 3.5 & 2.3800 \\
\hline & Moderately & 105 & 52.5 & \\
\hline & Extremely & 88 & 44.0 & \\
\hline \multirow[t]{3}{*}{ Motivates the player } & Not at all & 14 & 7.0 & 2.3100 \\
\hline & Moderately & 97 & 48.5 & \\
\hline & Extremely & 89 & 44.5 & \\
\hline \multirow{3}{*}{$\begin{array}{l}\text { Develops unity within a } \\
\text { team }\end{array}$} & Not at all & 6 & 3.0 & \\
\hline & Moderately & 108 & 54.0 & 2.3800 \\
\hline & Extremely & 86 & 43.0 & \\
\hline develop & Not at all & 5 & 2.0 & \\
\hline \multirow[t]{2}{*}{ Confidence of player } & Moderately & 105 & 52.5 & 2.4500 \\
\hline & Extremely & 90 & 45.0 & \\
\hline \multirow{3}{*}{$\begin{array}{l}\text { Builds Confidence of } \\
\text { the player }\end{array}$} & Not at all & 8 & 4.0 & \\
\hline & Moderately & 78 & 39.0 & \\
\hline & Extremely & 114 & 57.0 & 2.4900 \\
\hline
\end{tabular}

Table-1 we have found that the majority of the respondents have opted moderately in $1^{\text {st }}$ item, $3^{\text {rd }}, 4^{\text {th }}$ $5^{\text {th }}$ and $7^{\text {th }}$ items and extremely in $2^{\text {nd }}$ and $7^{\text {th }}$ items respectively which show the closest effect of democratic coaching on the motivation of Badminton student-players

\section{Chi-square Statistics}

Ho Democratic coaching style affects negatively on the motivation for student-players of Badminton.

The experiment of Null Hypothesis was performed through the utilization of Chi-square and saw as rejected, as the Chi-square measurement of the announcement of all qualities were bigger than the basic Chi-Square Value is (5.99) with $\mathrm{df}=2$ and $\chi 2=49.040$, as appeared in (Fig. 1).

Figure-1. shows the aftereffect of the chi-square test, the figure shows that the invalid theory was rejected.

$\mathrm{df}=2$

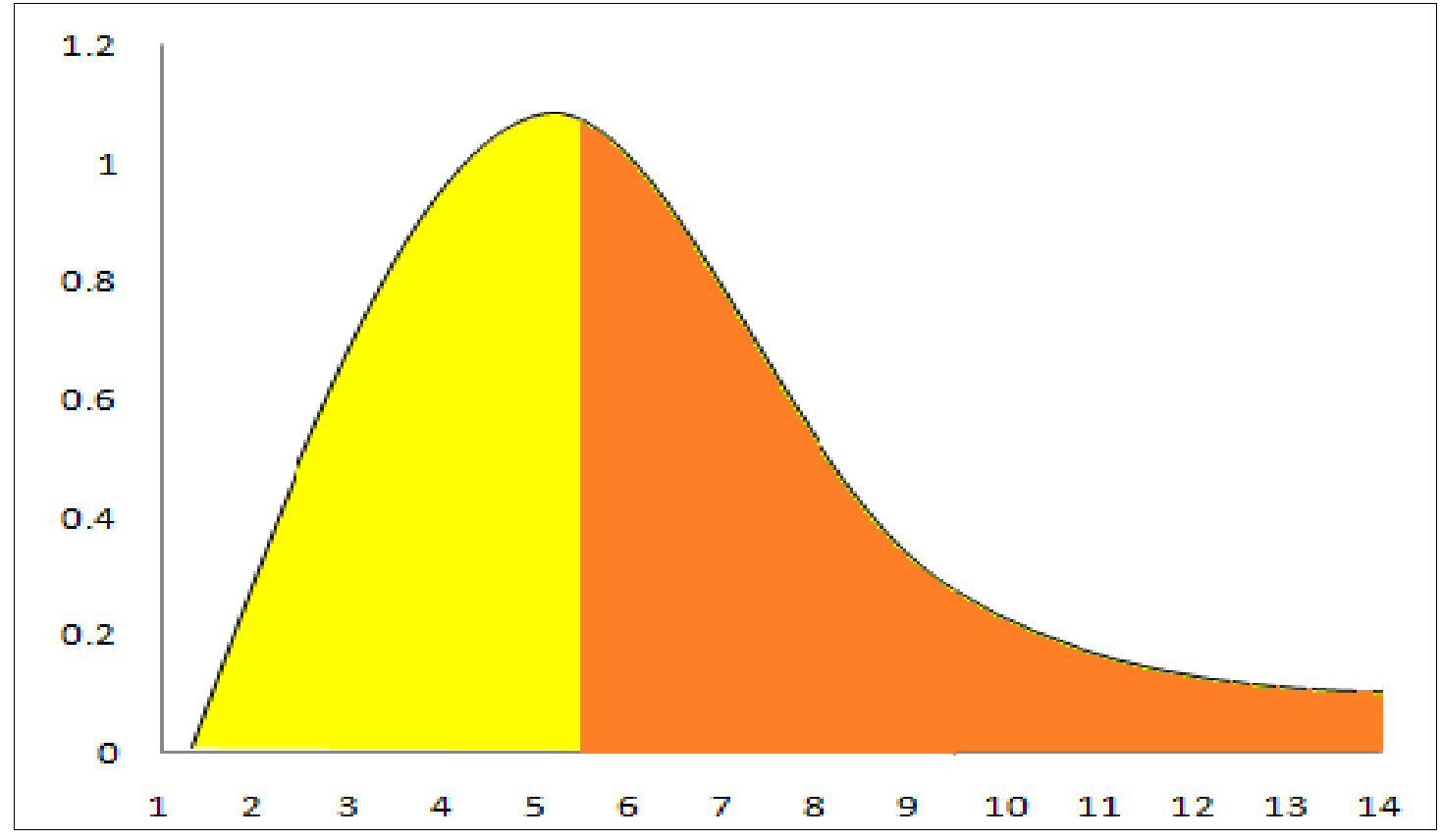




\section{Chi-square Statistic all items values are Larger than the Critical Chi-Square Value is (5.99) with $\mathbf{d f}=\mathbf{2}$ \\ Discussion}

The democratic coaching style and its effect on the motivation of Badminton players were investigated through the coaching efficacy scale (Feltz et al., 1999) as altered by Kavassanu et al., 2008 and Myers et al., 2009 as an information assortment tool that came about the comparable factor game-plan as the genuine progress. Applying a similar degree, Myers closed by a party (Myers et al., 2009) also examined the coaching efficacy scale (CES) to separate the appraisals of players for the capacity of their guides to influence the motivation of Badminton-players. The eventual outcomes of the present research show the improvement in the domain of care with the latest appraisal of energetic establishments of the thought for peering out the authentic data stressed over the effect of preparing in the field of sports at the College level while applying the CES. The determinant was impelled, support in a social perspective and objective arranged lead, in target achievements, limit and assurance of the players and execution of affiliations required by the players, focuses, and goals on the quantitative of tracks and duty (Ryan \& Tipu, 2013). The conduct changes in the players in social and mental perspective through preparing and the impacts of instructing has made idea starting late with different assessments exhibiting noteworthy consequences of this advancement for investigating the training on players (Feltz et al., 1999).

Fundamentally, past examination as this has not been dissected at Sukkur, Sindh, or despite the way that in Pakistan to take a look at the impacts of just coaching style on the motivation of Badminton-players, the scale to which they fluctuate from educator's reports related with effects of training. The flow examination is thought to fill a short gap in the field of exploration in coaching. The training in sports, its strategies for coaching, and its customary methodology have been exhibited for influencing once a comfort level for better execution (Horn, 2008). These outcomes are steady with past examinations, where conscience motivation was related with on edge states and a more noteworthy worry for execution (Pensgaard, \& Roberts, 2002). The things of the scale as in affirmed scale were applied, whereby mentioning that the Badminton players assess how their coaches were able to impact inspiration of the player, in any case, the investigator mentioned that the contenders point out at what entirety the reasonable coach is effective or how that influence on the players through the training while simultaneously arranging instructional courses, preparing and despite the way that during play or at whatever other condition where the educating is possible. An improvement that inclines the impact of preparing is the reasonability of training. The relationship of training with players has been winding up being a degree to which the coach acknowledges an idea of having had an ability to influence the learning and presentation of concerned players and involves regions, motivation, game-strategy, game technique, competition, and character-building of the player. Impacts of democratic coaching style on the motivation of Badminton-players during competitions shows away, a mindset and direct of coaches with their players and steps of the guides while teaching for the competition aptitudes of player (Kavussanu et al., 2008).

Resultantly the game specialists and coaches will have the choice to grasp democratic coaching style at inter-class, inter-department, inter-collegiate, and inter-varsity level of training, coaching camps, and competitions to encourage and to improve the players' competitional aptitudes. A trainer or a coach should have the ability to get a handle on the essentials of the players to apply their full capacity and physical limit and to make a more grounded relationship between players and the coach. Thusly; the activity of a coach is to make a degree of execution of players and to create natural components as an instrument to push the uplifting manner of the player and the investigation of this assessment will permit the stressed to explain these explored real factors with the guides and the coaches to grasp and use to improve players' motivation. The hugeness of prominence based coaching with the competition capacities of the players is significantly between subordinate games, for instance, Badminton has been made in the composition, these results add to enduring it as mental establishments and this is a central examination on Badminton preparing sufficiency at Sukkur Region Sindh. Also to understand the data on reasonable training and its sufficiency for the player can have a different propensity for coaching stressed over the players.

\section{Conclusion}

An investigation of democratic coaching with regards to its effects on Badminton-players in the rivalries has a key activity in the field of sports. The notoriety based preparation is seen as an 
incredible technique for improving the different capacities of the players all through the world including Pakistan. At the current status, it was to find its impact on the motivation of the player. The relationship was seen between University players and College Players in all elements of favored administration. The current examination demonstrates that certainly there is a positive impact of democratic coaching style on the motivation of student-players.

\section{Recommendations}

The exploration is principally centered on the local badminton players, in this way, the further examination can adjust about contrasting and global players. The exploration can adjust more examination like outcome investigation as indicated by coaches' character and comprehend the distinction of players feeling body vitality. It tends to be looked at as a significant heading for further exploration. The assessment of the momentum research as a relationship of democratic coaching style with the inspiration of Badminton players and the focuses expected for future investigates related to coaching, impacts of coaching, preparing with regards to authority, the suitability of as on various instructing, teaching regions can be ensured. Plus, keeping in observe the current assessment, it is proposed that it will, in general, be applied and followed by the coaches and the trainers in sports programs similarly as by the educators for the improvement of the degree of motivation of the players and all preparation spaces that aren't simply related with the Badminton match-up however the player's everything being equal.

\section{References}

Alam, F.H., Choudhary, Ch., Thepadungporn, A., Subic, and Khan M.M.K. (2009). International School of Aerospace, Mechanical and Manufacturing Engineering and built environment, Central queen's land University Rockhampton Australia. J. Mech. and Material Eng., 4, pp. 266-272.

Chiu, L. K., Nor, I.M., Najib, A. M., and Khor, P. H. (2014). Student-athletes' Evaluation of Coaches' Coaching Competencies and Their Sports Achievement Motivation. Review of European Studies; Vol. 6, No.2; Pp. 17-29.

Crespo, M. (2002). Tennis Psychology: An overview and update. Newsletter of Society for Tennis Medicine and Science, 5: 12.

Deci, E.L., and Ryan, R.M. (2000). The "what" and "why" of goal pursuits: Human needs and the self-determination of behavior. Psychol Inq. 11(4); pp. 227-68.

Duda, J. L. (2001). Achievement goal research in sport: Pushing the boundaries and clarifying some misunderstandings. In G. C. Roberts (Ed.), Advances in motivation in sport and exercise (pp. 129 182). Champaign, IL: Human Kinetics.

Ericsson, K.A., Krampe RT, and Tesch-Romer C. (1993). The role of deliberate practice in the acquisition of expert performance. Psychol Rev. 100(3); pp.363-406.

Feltz, D.L., Chase, M.A., Moritz, S.E., and Sullivan, P.J. (1999). A conceptual model of coaching efficacy: Preliminary investigation and instrument development. Journal of Educational Psychology, 91(4): pp. 765-776.

Fouss, D. G., and Troppmann, R. J. (1981). Effective coaching: A psychological approach. New York: John Wiley \& Sons.

Gualberto, C.J., and M.S. Wiggins, (2008). Direction and intensity of trait anxiety as predictors of burning out among collegiate athletes.Journal of Sport Psychology.Murray State University.https://www.toppr.com/guides/essays/essay-on-my-favorite-game-badminton/

Horn, T.S., (2008).Coaching effectiveness in the sports domain. In: T.S. Horn (Ed.), Advances in sport psychology (pp. 239-267). Champaign, IL: Human Kinetics.

Ivanova, N. L., Aleksandr A., and Korostelev. (2019). The impact of a competitive approach on students' motivation in sports. J. Amazon Investigation. Vol. 8(18); pp. 483-490.

Jane, R., (2009). Coaching and Mentoring: What they are and how to make the most of them. New York: Bloomberg Press. ISBN 9781576603307. OCLC263978214.

Jowett, S., and Cockerill, I.M. (2002). Incompatibility in the coach-athlete relationship. In I.M. Cockerill (Ed.). Solutions in sport psychology. Pp.16-31.

Kavussanu, M., Boardly, I.D., Jutkiewiez, N., Vincent, S., and Ring C. (2008). The Coaching efficacy and coaching effectiveness. The Sports Psycho. 22(4): pp. 383-404. 
Keatlholetswe, L., \& Malete, L. (2019).Coaching Efficacy, Player Perceptions of Coaches' Leadership Styles, and Team Performance in Premier League Soccer. Res. Q. Exerc. Sport., 90, Pp.7179.

Khan, Z., Zeeshan, H., \& Naseem A. (2011). Gender difference in achievement motivation of intervarsity level badminton players.J. Of Physical Education and Sport.11 (3).pp.255 - 258.

Light, R.L., and Harvey, S. (2017). Positive pedagogy for sports coaching. Sport Educ. Soc., 22, Pp. 271-287.

Magee, J., \& Galinsky, A.D. (2008). Social hierarchy: The self-reinforcing nature of power and status. Acad. Manag. Ann. Vol. 2, Pp. 351-398.

McDonnell, J. (2016). Scaffolding Practices: A study of design practitioner engagement in design education. Design studies, special issue; design review conversations, 45 (part A), pp 9-29.

Mitchell, S.A., Oslin J.L., \& Griffin L.L. (2006). Teaching sport concepts and skills: a tactical games approach. Champaign: Human Kinetics. vol. 1.

Myers, N.D., E.W. Wolfe, \& Feltz D.L. (2009). An evaluation of the Psychometric Properties of exercise science, 9(3): pp. 133-105.

Myers, N. D., Wolfe, E. W., Maier, K. S., Felt, D. L., \& Reckase, M. D. (2006). Athletes' evaluation of their head coach's coaching competency. Research Quarterly for Exercise and Sport, 77(1), 111-121. http://dx.doi.org/10.1080/02701367.2006.10599337.

Nazarudin, M. Fauzee, O. Jamalis, M. Geok, K., \& Din, A. (2009).Coaching leadership styles and athlete satisfaction among the Malaysian University Basketball team. Res. J. Int. Stud., 9, Pp. 4-11.

Oberle, E., \& Schonert-Reichl, K.A. (2016). Stress contagion in the classroom? The link between classroom teacher burnout and morning cortisol in elementary school students. Soc. Sci. Med. 2016, 159, pp. 30-37.

Olusoga, P., Butt, J., Hays, K., \& Maynard, I. (2009). Stress in elite sports coaching: Identifying stressors. J. Appl. Sport Psychol., 21. Pp. 442-459.

Pensgaard, A., and Roberts, G. (2002). Elite athletes' experiences of the motivational climate: The coach matters. Scand. J. Med. Sci. Sports. 12, Pp. 54-59.

Ramirez, F., Daves \& Paul H. (2010). A motivation case study of four badminton players settle and intrinsically motivated badminton performance. Pol. J. Sports tourism. Vol. 17, pp. 239-244

Roberts, G. C. (2001). Understanding the dynamics of motivation in physical activity: The influence of achievement goals on motivational processes.In G. C. Roberts (Ed.), Advances in motivation in sport and exercise (pp. 1 50). Champaign, IL: Human Kinetics.

Ryan, J.C., \& Tipu S.A. (2013). Leadership effects on innovation propensity: A two-factor full range leadership model, Journal of Business Research, 66, pp. 2116-2129.

Sallis, J. F., Prochaska, J. J., \& Taylor, W. C. (2000). A review of correlates of physical activity of children and adolescents. Medicine and Science in Sports \& Exercise.Vol. 32, pp. 963975.

Shariff, A.H., George, J., \& Ramlan, A.A. (2009). Musculoskeletal injuries among Malaysian Badminton players. Singapore Med. J., 50(11): pp. 1095-1097.

Van Duijvenvoorde, A.C., Peters, S., Braams, B.R., \& Crone, E.A. (2016). What motivates adolescents? Neural responses to rewards and their influence on adolescents' risk-taking, learning, and cognitive control.Neuro sci. Bio Behav.Rev., 70, Pp.135-147.

Weinberg, R.S., \& Gould, D. (2003). Foundations of sport and exercise psychology (3rded.) Champaign, IL: Human Kinetics. 